(51); of the extraordinarily fluid series of registers and idioms in which EdgarTom speaks (chapter 8, "Tom's Voices," and chapter 10, "Tom's Places"); of the scene in which Edgar-Tom leads the blinded Gloucester (chapter 14, "Shuttered Genealogy"); and of the duel between Edgar and Edmund (221-24). Because of readings like this, I will put Lear on my undergraduate syllabus next year for the first time since I can't remember when. I always avoid the play because I feel like students don't get it and I don't know how to tell them what they are supposed to get. Poor Tom has changed this; it has given me a provocative way of thinking about Lear, and an exciting, challenging model for reading it (to follow and to resist) which I did not have before.

JEREMY LOPEZ

University of Toronto

\title{
Riche, Barnabe.
}

\section{The Adventures of Brusanus, Prince of Hungaria (1592).}

Ed. with intro. and annotations by Joseph Khoury. Publications of the Barnabe Riche Society. Toronto: Centre for Reformation and Renaissance Studies, 2014. Pp. 383. ISBN 978-0-7727-2144-0 (paperback) \$28.

The number of pages listed above is misleading, as most of the pages in this edition of Barnabe Riche's very obscure Brusanus, Prince of Hungaria are taken up by Joseph Khoury's introduction. The tale itself is relatively short-certainly by the standards of some of the most famous Renaissance prose narratives-but it is remarkable for its variety. Khoury's thorough and perceptive introduction shows us exactly how rich Riche's tale is. Perhaps most valuably, while Khoury very successfully introduces the story and places it in a number of contexts, he leaves a great deal of scope for future scholars. Brusanus is an interesting story that deserves to be better known.

Much of the text's inclusive character can be found in its generic variety. As Khoury points out, the work can be classified in a number of ways: it is a narrative of male friendship, a love story, a text in the mirror for princes tradition, and an entry in the querelle des femmes, to name only the most obvious generic labels that could be applied to this tale. As well, Riche's text has considerable stylistic variety, changing from a very skilful pastiche of euphuism to 
a plainer and sometimes quite funny style. The choice of euphuism may seem odd in a book that dates from the early 1590s, after the popularity of Lyly's distinctive style had waned, but I think that Riche uses this style not primarily for decorative effect but mainly for thematic effect. Khoury comments briefly on this aspect of Brusanus-perhaps future work on this tale will take up this question.

Insofar as Riche's narrative has been known up to now, it has been as one of the sources for Shakespeare's Measure for Measure. In this case, as so often, Shakespeare's knowledge and use of the prose fiction of his time has helped to prevent Renaissance prose fiction from passing into complete obscurity. Riche is worth knowing for his own sake, however, and this edition of Brusanus should help his reputation. In this connection, I am encouraged to note that one of the most valuable aspects of Khoury's introduction is that he focuses on Riche as someone who uses sources and not just as someone who was a source for a writer in whom we are more interested. The main example here is Riche's use of Robert Greene's Gwydonius: The Carde of Fancie, itself a work modelled (however satirically) on Lyly's Euphues. With great detail and perception, Khoury shows how carefully Riche used Gwydonius; he demonstrates that this use should not be taken as plagiarism, but rather as a far-reaching engagement with and alteration of Greene's narrative.

For me, this was the most interesting part of Khoury's introduction. He makes the argument that Brusanus can perhaps best be appreciated as a work of very subtle intertextuality. I found this argument-made both in the introduction and in his very careful and detailed annotations-entirely persuasive. Like many Renaissance literary texts (and, to some extent, like most literary texts), Riche's narrative shows that what we call intertextuality could also be called interdependence. Khoury demonstrates that for Riche, works like Euphues and Gwydonius function not only as starting points but also as points of reference: throughout Brusanus, Riche returns to these texts-both stylistically and thematically-in order to situate his own text, one that is simultaneously the same as and different from these (and other) sources. As Khoury demonstrates, one of the potential uses of Brusanus, both in the classroom and in scholarly discussion, could be to stimulate discussions of Renaissance concepts of novelty, originality, and authorship.

So far my discussion of Brusanus has concentrated on its importance to literary history and to a number of critical debates within Renaissance literary 
studies. I do not want to give the impression that Riche's narrative is only worthy, however: Brusanus is an engaging story that easily holds the attention and is pleasurable to read. I think it would work well in a variety of university courses, both in the context of Renaissance studies and in the context of theories of adaptation and intertextuality. Khoury's careful editing has resulted in a very usable text.

Riche himself had a remarkable and varied career both as a writer and as a soldier. Unfortunately, he was never able to obtain financial security or even a reasonable pension for all his military labours. As Khoury points out, we can see these issues near the end of the narrative in Riche's detailing of Dorestus's rewarding of the soldiers who fought for him. Riche's financial woes cannot be remedied now, but it seems like an act of justice to restore this valuable narrative to print. It is a welcome addition to the ever-increasing canon of Renaissance prose fiction in scholarly and relatively cheap editions.

STEPHEN GUY-BRAY

University of British Columbia

\section{Roberts, David.}

\section{Restoration Plays and Players: An Introduction.}

Cambridge, UK: Cambridge University Press, 2014. Pp. ix, $252+12$ ill. ISBN 978-1-107-61797-1 (paperback) \$30.95.

David Roberts's Restoration Plays and Players is a wide-ranging and yet laudably lucid introduction to the world of Restoration theatre (1660-1714). Though it targets an undergraduate audience, Roberts's theatrical primer will be a welcome addition to any bookshelf for teachers of later seventeenth-century drama. The book's successive chapters cover almost every imaginable topicplaywrights, companies, actors and acting, playhouses, audiences and critics, texts and publishers, and revivals and adaptations. Each chapter begins with a broad discussion of its central topic across the period and is closed by a series of compact case studies illustrating, for instance, how a company's managerial ethos or cast of actors shaped the drama written and produced.

The finest and most useful chapter, in my view, and the one that effectively serves as the book's introduction, is its second, "The Life Cycle of the 